REF - ISSN 1808-0804 Vol. IX (3), 1 - 15, 2012.

\title{
DESENVOLVIMENTO DE UM GEL GENGIVAL A PARTIR DO EXTRATO BRUTO SECO DE Passiflora edulis Sims
}

DEVELOPMENT OF A GEL GINGIVAL FROM EXTRACT DRY Passiflora edulis Sims

DESARROLLO DE UN GEL GINGIVAL DE EXTRACTO SECO DE Passiflora edulis Sims

\author{
Arquimedes Fernandes de Melo ${ }^{1 *}$, Jessika Mayara Tenório Cavalcante Muricy ${ }^{2}$ e \\ Rafaela Ferreira dos Santos ${ }^{2}$ \\ ${ }^{1}$ Docente e Orientador na Universidade Federal de Pernambuco (UFPE) \\ ${ }^{2}$ Farmacêutica em Caruaru, Pernambuco, Brasil \\ *autor para correspondência: meloufpe@yahoo.com.br
}

Recebido em 19/10/2011, Aceito em 24/08/2012.

\begin{abstract}
Resumo
A erupção dentaria é caracterizada pela movimentação dinâmica e continua do dente durante a sua formação, até atingir a sua posição funcional na cavidade oral. Nesse estágio a criança apresenta manifestações clínicas como, febre, diarréia, irritabilidade, inapetência, salivação excessiva, sono agitado ou insônia, entre outros, ocorrendo isoladamente ou associados, devido ao processo inflamatório que acomete a criança. Por isso, a atenção à saúde bucal das mesmas deve ser iniciada a partir do seu nascimento, com a finalidade de manter a saúde bucal, dentro de uma filosofia e tratamento
\end{abstract}


de Melo, A. F.; Muricy, J. M. T. C.; Santos, R. F. Revista Eletrônica de Farmácia Vol. IX (3), $1-15,2012$.

educativo-preventivo. Diante disso, por apresentar atividades analgésica, ansiolítica, antiinflamatória dentre outras, o maracujá, Passiflora edulis foi selecionado para o desenvolvimento da formulação de um gel gengival que atenda os requisitos necessários para manutenção da estabilidade da fórmula. Para isso foram realizados estudos de estabilidade acelerada, com 24horas, 10, 20, 30, 40, 50 e 60 dias, em três condições distintas, estufa $40^{\circ} \mathrm{C}$, geladeira $8^{\circ} \mathrm{C}$ e temperatura ambiente, após a produção do gel base e incorporação do extrato. Verificou-se que, em temperatura ambiente, o gel demonstrou ótimos aspectos organolépticos e físico-químicos. Então evidencia-se que o produto final deve ser acondicionado em temperatura ambiente sem mudança de temperatura.

Palavras Chaves: Fitoterapia, Erupção dental, Inflamação.

\section{Abstract}

The dental eruption is characterized by dynamic movement of the tooth and continues during your training, until it reaches its functional position in the oral cavity. At this stage the child presents symptoms such as fever, diarrhea, irritability, poor appetite, excessive salivation, restless sleep or insomnia, among others, occurring alone or combined, because the inflammatory process that affects the child. Therefore, the oral health of these should be started from its birth, in order to maintain oral health, within a philosophy of education and prevention and treatment. Given this, by having analgesic, anxiolytic, anti-inflammatory and others, passion fruit, Passiflora edulis was selected for the development of a gel formulation of gum that meets the requirements for maintaining stability of the formula. For that were accelerated stability studies, with 24 hours, $10,20,30,40,50$ and 60 days in three different conditions, oven $40^{\circ} \mathrm{C}$, refrigerator $8^{\circ} \mathrm{C}$ and room temperature, after production of the gel base and incorporation of the extract. It was found that, at room temperature, the gel showed excellent organoleptic aspects and physical chemists. So it is evident that the end product should be stored in room temperature without a temperature change.

Descriptors: Phytotherapy, Tooth Eruption, Passiflora.

\section{Resumen}

La erupción dental se caracteriza por el movimiento dinámico del diente y continúa durante su formación, hasta que alcanza su posición funcional en la cavidad oral. En esta etapa el niño presenta síntomas como fiebre, diarrea, irritabilidad, falta de apetito, salivación excesiva, alteraciones del sueño o insomnio, entre otros, que se producen solos o combinados, debido a que el proceso inflamatorio que afecta al niño. Por lo tanto, la salud oral de estos se debe iniciar desde su nacimiento, con el fin de mantener la salud oral, dentro de una filosofía de la educación y la prevención y el tratamiento. Teniendo 
de Melo, A. F.; Muricy, J. M. T. C.; Santos, R. F. Revista Eletrônica de Farmácia Vol. IX (3), $1-15,2012$.

en cuenta esto, por tener analgésicos, ansiolíticos fruta, la pasión anti-inflamatorios y otros, Passiflora edulis fue seleccionado para el desarrollo de una formulación en gel de las encías que cumple los requisitos para mantener la estabilidad de la fórmula. Para ello, se aceleraron los estudios de estabilidad, con 24 horas, 10, 20, 30, 40, 50 y 60 días en tres condiciones diferentes, estufa a $40^{\circ} \mathrm{C}$, refrigerador a $8^{\circ} \mathrm{C}$ y temperatura ambiente, después de la producción de la base de gel y la incorporación del extracto. Se encontró que, a temperatura ambiente, el gel mostró excelentes aspectos organolépticos y físicoquímicos. Entonces es evidente que el producto final debe ser almacenado a temperatura ambiente sin um cambio de temperatura.

Descriptores: Fitoterapia, Erupción Dental, Passiflora.

\section{Introdução}

A erupção dental é um processo fisiológico onde o dente, migra de uma posição intra-óssea e atinge uma posição funcional na cavidade bucal. O processo pode ser dividido em três fases: préeruptiva, eruptiva e pós-eruptival. A primeira, intra-óssea, estende-se do rompimento do pedículo até a formação completa da coroa e, nesta fase, não há movimentação do germe dental ${ }^{(1,2)}$. A fase eruptiva envolve o movimento intraósseo do dente através do processo de reabsorção dos tecidos que cobrem a coroa criando uma trajetória de erupção. A terceira fase é totalmente extra-óssea e se inicia quando o dente entra em oclusão com o antagonista, terminando com a perda do elemento dental, sua extração, ou com a morte do indivíduo ${ }^{(3,4)}$.

Antes da fase eruptiva há a liberação de proteínas da matriz do esmalte do dente (ameloblastos), levando a uma reação imunológica no qual o acúmulo de mastócitos ao redor do dente em erupção, produz uma reação de hipersensibilidade ${ }^{(5)}$. Esta pode estar diretamente relacionada com os sinais clínicos observados durante a erupção, como eritema, salivação e coceira. Alguns estudos demonstraram que o processo de erupção do dente é um risco para a criança, além de muito desconfortável, pois apresenta gengiva edemaciada e sensível a palpação, já que um processo inflamatório é instalado devido à agressão ao tecido. Os lactentes passam então a morder seus dedos, objetos e lábios, a apresentar irritabilidade, choro noturno e salivação em excesso ${ }^{(3,5)}$.

Visto que uma gama imensa de estudos científicos demonstra as propriedades, calmante, sedativo e antiinflamatório do maracujá, o mesmo tem potencial para que seu extrato seja utilizado em formulações de géis gengivais. O histórico da Passiflora definiu-se no início da expansão européia na exploração espanhola ao Novo Mundo. Sendo a planta americana que 
de Melo, A. F.; Muricy, J. M. T. C.; Santos, R. F. Revista Eletrônica de Farmácia Vol. IX (3), $1-15,2012$.

causou maior admiração aos colonizadores espanhóis dos séculos XVI e XVII, não só pela beleza de suas flores, mas também pelo misticismo de sua morfologia. Sua propagação tem início com um sentido religioso e expressão literária, que fez de sua existência uma notícia de significado cultural marcante. A princípio conhecia-se esta planta com o nome de granadilla, porque seu fruto se parecia com a Punica granatum; mais tarde recebeu a denominação de Passiflora, passionária ou flor da paixão (flor de la pasión). Esta planta tem sido utilizado como analgésico, antiespasmódico, anti-asmáticos, vermicida e sedativo no Brasil( $^{(6)}$.

$\mathrm{Na}$ maioria das referências ao uso de Passiflora na medicina popular são abordadas as propriedades psicotrópicas, efeitos no Sistema Nervoso Central, tais como, ansiolíticos, sedativos e anticonvulsivantes. Por outro lado, alguns autores descrevem o uso da Passiflora spp. na medicina popular para o tratamento de doenças inflamatórias. As partes da planta mais utilizada são as partes aéreas, sem a presença das flores $^{(6,7,8)}$.

A administração sistêmica dessa espécie apresenta pronunciada ação antiinflamatória, caracterizada por inibição do influxo de leucócitos para a cavidade pleural associadas com bloqueio marcado de mieloperoxidase, óxido nítrico, níveis de fator de necrose tumoral (TNF) e interleucina 1 (IL1) no modelo de inflamação aguda causada pela injeção de $\mathrm{Cg}$ no interior pleural. Além disso, o extrato foi eficaz na inibição de leucócitos na pleurisia induzida por bradicinina, histamina e substância $\mathrm{P}^{(9,10)}$.

Montanher $^{(9)}$ demonstrou em seus experimentos que a $P$. edulis tem propriedades semelhantes as da dexametasona pertencente à classe dos corticosteróides. Reduzindo os leucócitos, mieloperoxidase e níveis de óxido nítrico na primeira fase $(4 \mathrm{~h}) \mathrm{da}$ resposta inflamatória induzida pela carragenina em camundongos. Já na supressão dos níveis TNF e IL-1 $P$. edulis foi mais eficaz. $P$. edulis possui atividades neurofarmacológicas, tanto no sistema nervoso central como no sistema nervoso periférico sendo mostrada atividade melhor que o diazepam ${ }^{(13)}$. Atualmente existem estudos que comprovam a utilização da Passiflora edulis para tratar infecções e inflamações cutâneas em feridas abertas $^{(14)}$.

Estudos apontam com ênfase os efeitos antiinflamatórios dos flavonóides, por exemplo, alguns destes demonstraram que estas substâncias inibiam TNF inflamatórias em diferentes modelos de alergias. As investigações bioquímicas também mostraram que os flavonóides podem inibir tanto a ciclooxigenase como a lipoxigenase no metabolismo do ácido araquidônico devido a sua estrutura química ${ }^{(12)}$. E no que se refere à componentes químicos, as investigações anteriores do extrato 
de Melo, A. F.; Muricy, J. M. T. C.; Santos, R. F. Revista Eletrônica de Farmácia Vol. IX (3), $1-15,2012$.

aquoso, de Passiflora, preparado da mesma forma, revelou um elevado teor de flavonóides $(4,4 \%)^{(11)}$.

Os principais fitocomponentes de $P$. edulis são os glicosídeos, fenóis, alcalóides, carotenóides, antocianinas, componentes voláteis do petróleo como caproate hexila e butirato, e caproato de etila e butirato, aminoácidos, carboidratos, minerais como $\mathrm{Na}, \mathrm{K}, \mathrm{Mg}$, $\mathrm{Ca}, \mathrm{Zn}, \mathrm{Al}, \mathrm{Mn}, \mathrm{Fe}$, triterpenos e saponinas.

A gama de substâncias encontradas em apenas uma planta é a principal diferença entre um fitoterápico e um medicamento sintético. Os fármacos raramente são administrados nas formas de substâncias químicas puras, sendo normalmente veiculados em formulações ou especialidades farmacêuticas $^{(15)}$. Da mesma forma, o maracujá necessita ser veiculado adequadamente, para que possa ser administrado com facilidade e segurança, otimizando sua resposta terapêutica. Por outro lado, o desenvolvimento e a formulação apropriada de uma forma farmacêutica requerem a consideração das características físicas, químicas e biológicas de todos os princípios ativos e de todas as matérias-primas empregadas na elaboração do produto.

Paralelamente à eficácia e segurança de um produto acabado, considera-se a sua capacidade em manter, ao longo do prazo de validade, a dosagem terapêutica inalterada, sem que ocorra um aumento da toxicidade e formação de possíveis alterações nas propriedades organolépticas. Dessa forma, para a obtenção de uma formulação que mantenha suas propriedades originais dentro do prazo de validade estabelecido, são realizados previamente testes e ensaios na forma farmacêutica com o objetivo de obter informações sobre a estabilidade do princípio ativo presente, de modo a definir seu período máximo de armazenamento $^{(16)}$.

Nesse contexto, buscou-se desenvolver um gel gengival avaliando a capacidade de incorporação e a estabilidade física do mesmo à incorporação de uma solução hidroalcoólica de Passiflora edulis a 5\%.

\section{MÉTODOS}

\section{Tipologia do estudo e caracterização da amostra}

Por meio de um estudo longitudinal e descritivo selecionou-se de forma aleatória (partes aéreas) a amostra da Passiflora edulis, oriunda da Fazenda Palmeira da cidade de Camocim de São Félix - $P E$, no mês de novembro de 2010. A identificação da espécie foi realizada no Instituto Agronômico de Pernambuco-IPA e a exsicata foi depositada no Herbário do referido instituto, situado em Recife-PE. O número de tombamento da planta foi IPA85783. 
de Melo, A. F.; Muricy, J. M. T. C.; Santos, R. F. Revista Eletrônica de Farmácia Vol. IX (3), 1 - 15, 2012.

Foram utilizados $54 \mathrm{~g}$ do material para a extração com solução hidroalcoólica a 70\% (v/v). Após uma semana de maceração, processo mecânico que utiliza solventes para extrair os metabólitos, foi obtido o extrato bruto por filtração. O extrato foi colocado em evaporador rotativo $40^{\circ} \mathrm{C}$, para se obter o extrato seco que foi reduzido a pó e dividido para os testes farmacotécnicos e de estabilidade.

\section{Estudo Farmacotécnico}

Foram utilizadas técnicas preconizadas pelos compêndios oficiais e farmacopéias. Aqueceu-se a água à $70^{\circ} \mathrm{C}$ com solubilização dos componentes da formulação na sequência mostrada na tabela 01 até 0 propilenoglicol. Acrescentou-se lentamente o carbopol agitando-se com uma velocidade moderada, até a total dispersão. Posteriormente diminuímos a temperatura à $40^{\circ} \mathrm{C}$ e adicionamos o Germal previamente solubilizado em pequena quantidade de água. Por fim ajustou-se $\mathrm{opH}$ para 6,5 - 7, com a trietanolamina. O extrato bruto seco foi ressuspenso em água destilada e álcool absoluto, e incorporado imediatamente após a produção da formulação através de mistura geométrica até obter um produto uniforme. As amostras para teste de estabilidade foram acondicionadas em recipientes plásticos opacos com tampa, na quantidade de 30 gramas cada e devidamente identificadas (figura 1).

Figura 1 - Estudo de estabilidade

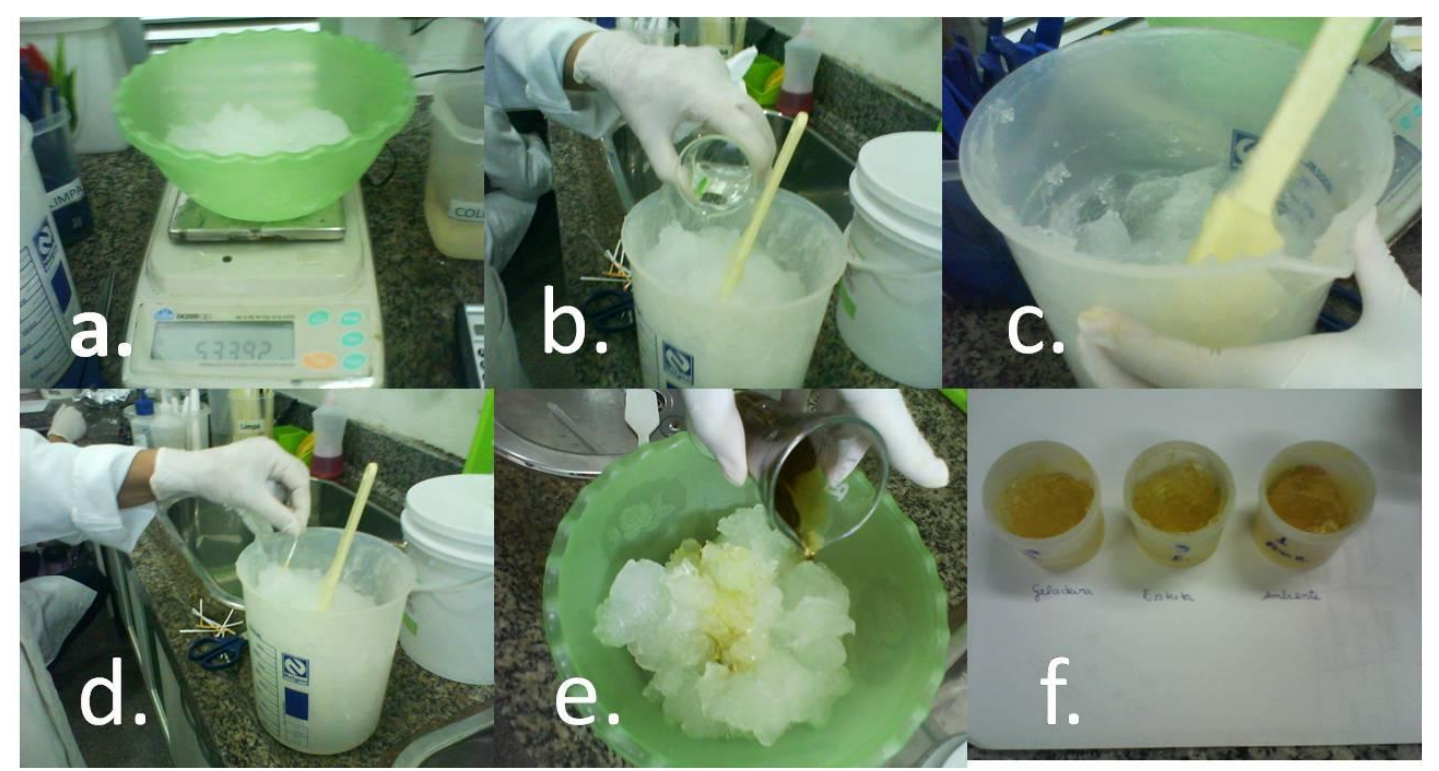


de Melo, A. F.; Muricy, J. M. T. C.; Santos, R. F. Revista Eletrônica de Farmácia Vol. IX (3), 1 - 15, 2012.

a. pesagem dos constituintes; b. adição dos constituintes; c. mistura dos constituintes; d. correção do pH; e. adição do extrato da planta; f. envase do produto acabado.

Tabela 1

\begin{tabular}{|ccc|}
\hline Componentes da formulação & Quantidade & Função \\
\hline Metilparabeno (nipagim) & $1,4 \mathrm{~g}$ & Preservante \\
Propilparabeno (nipasol) & $1,05 \mathrm{~g}$ & Preservante \\
EDTA Dissódico & $0,7 \mathrm{~g}$ & Quelante \\
Propilenoglicol & $14 \mathrm{~g}$ & Emoliente \\
Água deionizada & $\mathrm{qsp} 700 \mathrm{~g}$ & Veículo \\
Carbômero (Carbopol ultrez 10) & $14 \mathrm{~g}$ & Espessante \\
Imidazolidinil Uréia (Germal) & $0,7 \mathrm{~g}$ & Preservante \\
Trietanolamina & $\mathrm{qs}$ & Alcalinizante \\
\hline
\end{tabular}

\section{Estudo de Estabilidade}

As amostras foram submetidas a estudos de estabilidade acelerada de acordo com os procedimentos descritos no Guia de Estabilidade de Produtos Cosméticos $^{(16)}$, sendo armazenadas às condições de temperatura ambiente (20$\left.25^{\circ} \mathrm{C}\right)$; geladeira $\left(3-8{ }^{\circ} \mathrm{C}\right)$ e estufa $\left(40^{\circ} \mathrm{C}\right)$ para avaliar a aparência, cor, odor, $\mathrm{pH}$, viscosidade e espalhabilidade no período de 24 horas, $10,20,30,40$, 50 e 60 dias, após a produção da formulação. Em cada condição testada, foram utilizadas três amostras da formulação, com 30 gramas cada.

\section{Propriedades Organolépticas}

Foi realizada de maneira subjetiva, por comparação entre todas as amostras da preparação submetidas às diferentes condições. Foi definida como referência a amostra mantida sob temperatura ambiente. Para a avaliação da aparência, observamos níveis de alteração que são classificados em (I) normal, sem alteração; (II) levemente separado, levemente precipitado ou levemente turvo e (III) separado, precipitado ou turvo. A graduação dos níveis de alteração de cor e odor observada na formulação foi classificada de acordo com os seguintes critérios: (I) normal sem alteração; (II) levemente modificada; (III) modificada e (IV) intensamente modificada ${ }^{(16)}$.

\section{pH}

$\mathrm{O} \mathrm{pH}$ foi determinado por meio de técnica potenciométrica, com o equipamento SCHOTT FieldLab $\mathrm{pH}$ previamente calibrado na faixa de $\mathrm{pH}$ de 
de Melo, A. F.; Muricy, J. M. T. C.; Santos, R. F. Revista Eletrônica de Farmácia Vol. IX (3), $1-15,2012$.

4,0 e 7,0. Sendo as análises realizadas em triplicata.

\section{Determinação da espalhabilidade}

Foi empregada a metodologia descrita por Knorst ${ }^{(17)}$, que utiliza placas de vidro sobre uma escala de papel milimetrado para determinar a superfície que a amostra abrange através da medição dos diâmetros perpendiculares, com posterior cálculo do diâmetro médio. A espalhabilidade (Ei), a $24 \pm 2$ ${ }^{\circ} \mathrm{C}$, os cálculos foram realizados a partir da equação:

$$
\mathrm{Ei}=[(\mathrm{d} 2), \pi] / 4
$$

Considerou-se como $\mathrm{Ei}\left(\mathrm{mm}^{2}\right)$ a espalhabilidade da amostra para peso $i$ e $d$ o diâmetro médio $(\mathrm{mm})$ alcançado pela amostra após a sobreposição de cada placa. Os valores da espalhabilidade em função dos pesos adicionados foram determinados em triplicata, calculandose a média.

\section{Viscosidade}

Foi realizada a leitura das viscosidades aparentes, em triplicata, segundo metodologia internacional ASTM D2196-05(18), empregando viscosímetro rotativo de Brookfield de 6 velocidades. Selecionou-se velocidade de 0,3 rpm e spindle número 4. Previamente às leituras, todas as formulações foram acondicionadas à temperatura de $24 \pm 2$
${ }^{\circ} \mathrm{C}$, sendo $\mathrm{O}$ ensaio realizado em ambiente com a mesma faixa de temperatura.

\section{Ciclo gelo-degelo}

Amostras foram colocadas em estufa a $40^{\circ} \mathrm{C}$ por um período de 7 dias, depois foram transferidas para geladeira, onde permaneceram por 7 dias e, então, retornaram à estufa pelo mesmo período. Ao final desse ciclo, as amostras foram submetidas à ação de centrífuga a $3000 \mathrm{rpm}$ durante 45 minutos e avaliadas de acordo com os seguintes critérios: (1) sem separação de fases; (2) leve separação de fases; (3) notável separação de fases; (4) produto com $50 \%$ de separação e (5) produto com mais de $50 \%$ de separação(19).

\section{Estufa e centrífuga combinadas}

As amostras ficaram em estufa a $40{ }^{\circ} \mathrm{C}$ e após 24 e 168 horas alíquotas foram submetidas à ação da centrífuga durante 1 hora a 3000 rpm, sendo então avaliadas macroscopicamente de acordo com os critérios: (1) sem separação de fases; (2) leve separação de fases; (3) produto com $50 \%$ de separação; e (4) produto com mais de $50 \%$ de separação $^{(16)}$.

\section{RESULTADOS E DISCUSSÃO}

O gel escolhido para a incorporação do extrato foi o carbopol ultrez 10 , onde 
de Melo, A. F.; Muricy, J. M. T. C.; Santos, R. F. Revista Eletrônica de Farmácia Vol. IX (3), 1 - 15, 2012.

em concentração de 5\% de Passiflora, apresentou aspecto brilhoso, de coloração amarelada com odor característico da parte utilizada, sem quebra da forma farmacêutica.

Imediatamente após

a incorporação do extrato à base, amostras de $30 \mathrm{~g}$ foram colocadas em recipientes fechados e acondicionados em três situações distintas, estufa à $40^{\circ} \mathrm{C}$, geladeira à $8^{\circ} \mathrm{C}$ e temperatura ambiente que permitiram a análise da estabilidade do produto.

O gel que foi colocado em temperatura ambiente demonstrou aparência e odor normal até o sexagésimo dia, com leve modificação da cor a partir do décimo dia de análise, mantendo-se até a última. Já em geladeira foi observada uma leve separação do gel a partir do décimo dia com modificação do odor e da cor no vigésimo dia mantendo-se até a última análise. Quando em estufa também apresentou leve separação no décimo dia em diante, com modificação da cor no quadragésimo dia ficando assim até o sexagésimo dia, e sua coloração foi modificada a partir do vigésimo dia. A tabela 2 e figura 2 representam o estado final do produto acabado, após 60 dias de análise.

Tabela 2

\begin{tabular}{|cccc|}
\hline \multicolumn{4}{c|}{ Propriedades Organolépticas } \\
\hline Aparência & Cor & Odor \\
T. Ambiente & Norm. & Lev. Mod. & Norm. \\
Geladeira & Lev. Sep. & Lev. Mod. & Mod. \\
Estufa & Lev. Sep. & Mod. & Mod. \\
\hline
\end{tabular}

Norm. (normal), Lev. Sep. (levemente separado), Lev. Mod. (levemente modificado), Mod. (modificado).

Figura 2 - Produto final acabado envasado

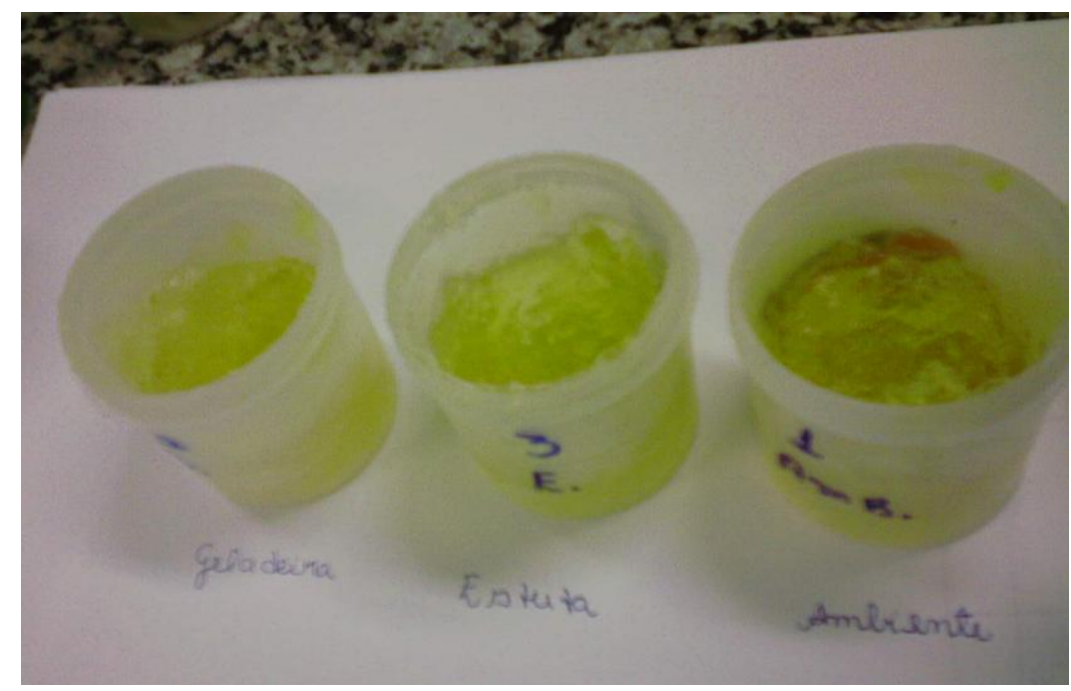


$\mathrm{O} \mathrm{pH}$ em temperatura ambiente teve uma média de 7,17 ao longo das 7 análises realizadas, em condição de estufa a média foi de 7,91 e na de geladeira foi 6.9. Após formulação o gel apresentava $\mathrm{pH} 7$, podendo variar de 7 para 7,5. Dessa forma, observou-se que apenas em temperatura ambiente permaneceu nessa faixa aceitável de variação (tabela 3 ).

Tabela 3

\begin{tabular}{|ccccccccc|}
\hline & \multicolumn{8}{c|}{$\mathrm{pH}$ das amostras } \\
& $\mathbf{2 4}$ & $\mathbf{1 0}$ & $\mathbf{2 0}$ & $\mathbf{3 0}$ & $\mathbf{4 0}$ & $\mathbf{5 0}$ & $\mathbf{6 0}$ & \\
& horas & dias & dias & dias & dias & dias & dias & Média \\
T. Ambiente & 6,7 & 6,85 & 6,85 & 7,5 & 7,35 & 7,45 & 7,5 & 7,17 \\
Geladeira & 6,6 & 6,75 & 6,8 & 6,8 & 7,1 & 7,1 & 7,15 & 6,9 \\
Estufa & 6,8 & 7,5 & 7,8 & 8,2 & 8,2 & 8,4 & 8,5 & 7,91 \\
\hline
\end{tabular}

A espalhabilidade juntamente com a viscosidade, serve para avaliar alterações nas características reológicas da formulação durante o estudo. No caso de semi-sólidos de uso tópico, a quantificação desse parâmetro é importante para acompanhar modificações na capacidade que a formulação tem de se espalhar ou abranger determinada área, o que pode facilitar ou dificultar sua aplicação, distribuição e/ou absorção(20). Antes do estudo de estabilidade, a formulação demonstrou condições táteis e sensoriais adequadas. Os gráficos 01 , 02 e 03, demonstram o comportamento do gel nas três condições analisadas onde se percebe a queda da espalhabilidade $e$ consequentemente da viscosidade do produto já que ambas estão correlacionadas. No entanto nas situações de geladeira e temperatura ambiente essa diminuição foi muito pequena o que não influencia na capacidade de distribuição e/ou absorção do mesmo. 
de Melo, A. F.; Muricy, J. M. T. C.; Santos, R. F. Revista Eletrônica de Farmácia Vol. IX (3), $1-15,2012$.

Gráfico 01

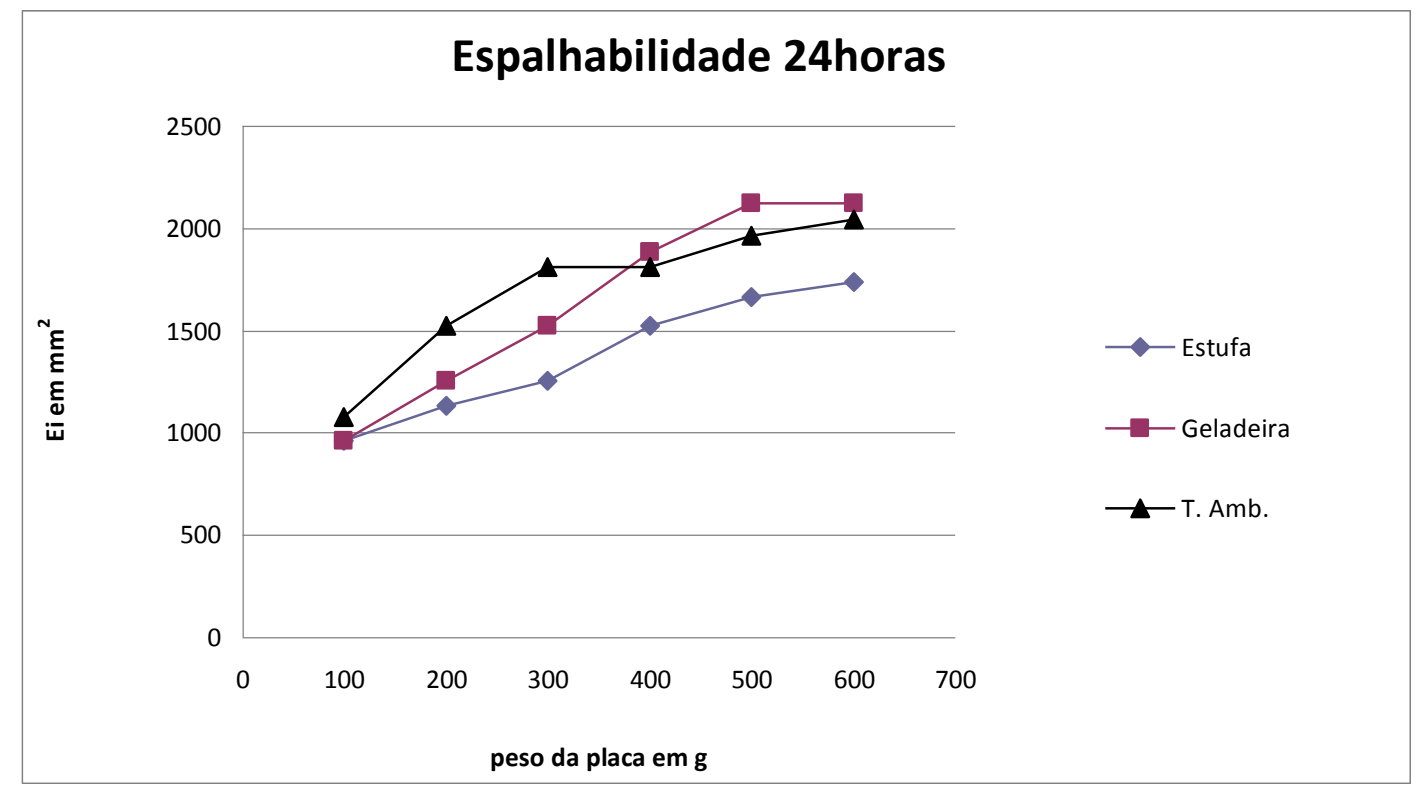

Gráfico 02

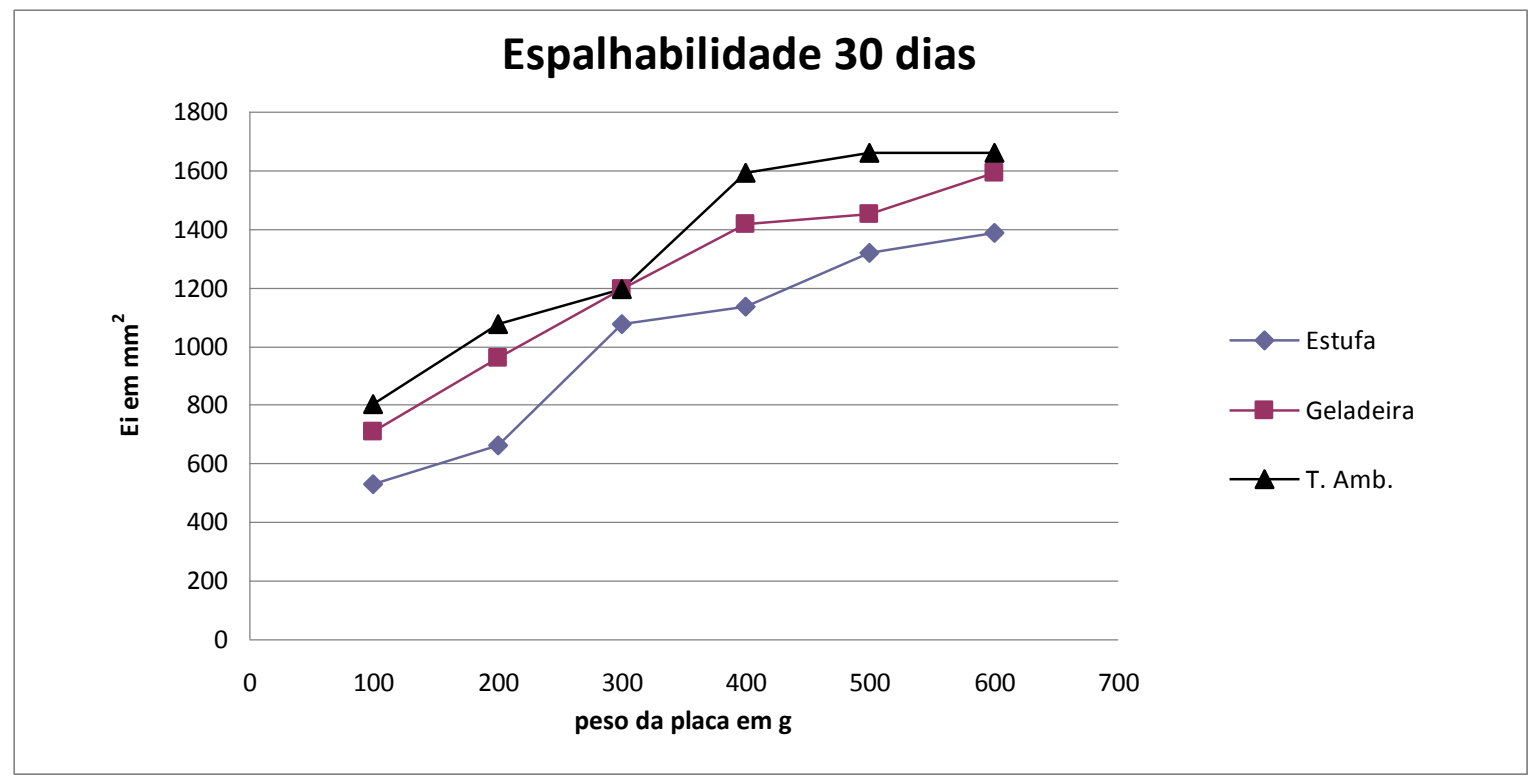


de Melo, A. F.; Muricy, J. M. T. C.; Santos, R. F. Revista Eletrônica de Farmácia Vol. IX (3), 1 - 15, 2012.

Gráfico 03

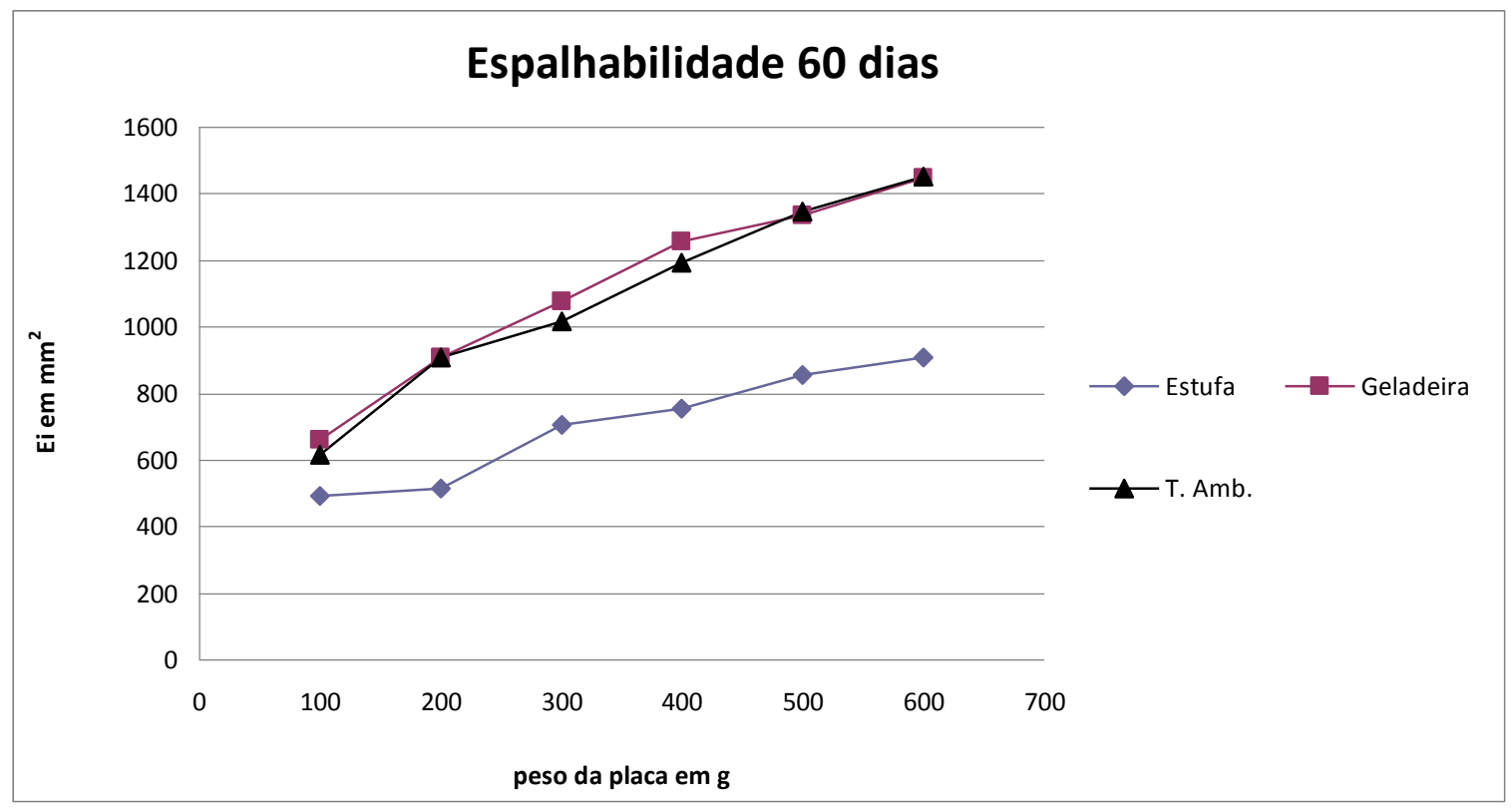

A viscosidade das amostras na três condições armazenadas, foi avaliada no viscosímetro rotativo de Brookfield de 6 velocidades, onde todas as velocidades foram testadas com o spindle $n^{\circ} 4$. No entanto, o gel demonstrou uma viscosidade acima da capacidade do mesmo, impossibilitando a determinação da viscosidade do produto.
Após ciclo gelo-degelo, o gel gengival, foi classificado em grau I, pois não se observou qualquer tipo de separação ou alteração da cor e odor no período de estudo. Para o teste de estufa centrífuga combinados não se observou qualquer tipo de alteração após o período de centrifugação, conforme verifica-se na figura 3 , sendo classificado em grau I. 
de Melo, A. F.; Muricy, J. M. T. C.; Santos, R. F. Revista Eletrônica de Farmácia Vol. IX (3), $1-15,2012$.

Figura 3 - Gel Gengival após ciclo gelo-degelo e teste de estufa centrífuga combinados.

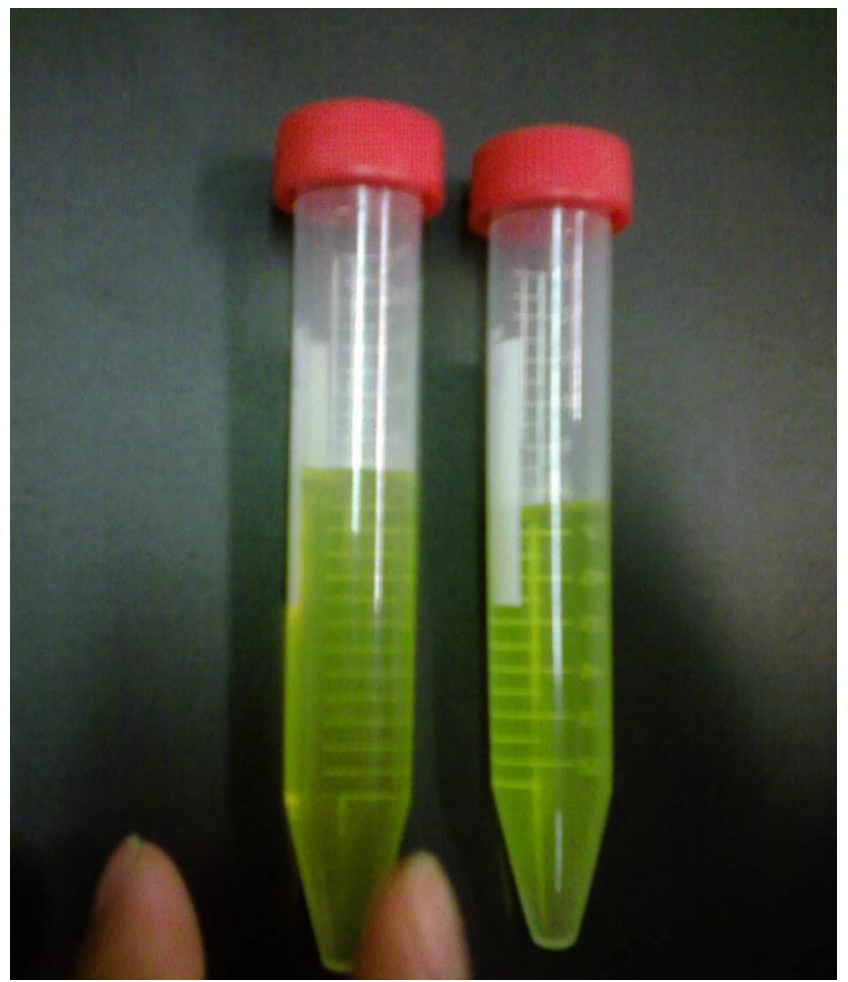

\section{CONCLUSÃO}

A formulação de gel incorporado de maracujá a $5 \% \quad(\mathrm{p} / \mathrm{p})$ apresentou excelente estabilidade na condição de temperatura ambiente, onde praticamente não apresentou sinais de alteração físico-química da formulação. Sua capacidade de incorporação e aceitação do extrato de Passiflora foi excelente, mantendo praticamente inalteradas as características de aparência, cor, odor, $\mathrm{pH}$, viscosidade e espalhabilidade, demonstrado assim que
- gel deve ser acondicionado em temperatura ambiente para manutenção de suas características, evitando situações de estresse de alta ou baixa temperatura.

Este trabalho dará suporte a
outros, pois os dados gerados
contribuirão para criar novas
perspectivas e direcionar futuros estudos
na tentativa de se obter uma formulação
de gel com maracujá otimizado, podendo
este dar suporte para estudos da
atividade, antiinflamatória e analgésica.

\section{REFERÊNCIAS BIBLIOGRÁFICAS}

1. Silva FWGP, Santos BM, Stuani AS, Mellara TS, Queiroz A M. Erupção dental: sintomatologia e tratamento. Pediatria. 2008;30(4):243-8; 
de Melo, A. F.; Muricy, J. M. T. C.; Santos, R. F. Revista Eletrônica de Farmácia Vol. IX (3), $1-15,2012$.

2. Diniz MB, Bolini PDA, Minarelli-Gaspar AM. Sintomas locais e sistêmicos relacionados à erupção de dentes decíduos. Rev. Paul. Pediatria. 2006;24(1):71-7;

3. Gaião LR. Saúde Bucal dos bebês nos primeiros seis meses de vida: o comportamento das mães atendidas pelo Programa Saúde da Família no Bairro Dom Expedito, Sobral - CE no ano de 2001. Aracajú: Universidade Estadual Vale do Acaraú-UVA/Escola de Formação em Saúde da Família; 2001;

4. Ximenes Neto FRG, Vasconcelos FM, Chagas MIO, Cunha ICKO, Sampaio JJC, Silva RCC. Nascimento da dentificação em crianças menores de um ano: análise do perfil, percepção e práticas maternas e suas implicações para a organização dos serviços de saúde. Biblioteca Las casas. 2010;6(1):12-28;

5. Pierce AM, Lindskog S, Hammarstrom L. IgE in postsecretory ameloblasts suggesting a hypersensitivity reaction at tooth eruption. ASDC J Dent Child. 1986;53:23-6;

6. Dhawan K, Kumar S, Sharma A. Comparative biological activity study on Passiflora incarnata and $P$. edulis. Fitoterapia. 2001;72:698-702;

7. Cervi AC. Passifloraceae do Brasil. Estudo do gênero Passiflora L., subgênero Passiflora. Fontqueria. 1997;2(45):1-92;

8. Souza MM, Pereira TNS, Vieira MLC. Cytogenetic Studies in Some Species of Passiflora L. (Passifloraceae): A Review Emphasizing Brazilian Species. Braz. arch. biol. technol. 2008; 51(2):247-258;

9. Montanher AB, Zucolotto SM, Schenkel EP, Frode TS. Evidence of anti-inflammatory effects of Passiflora edulis in an inflammation model. Journal of Ethnopharmacology. 2007;109:281-8;

10. Vargas AJ, Geremias DS, Provensi G, Fornari PE, Reginatto FH, Gosmann G, et. al. Passiflora alata and Passiflora edulis spray-dried aqueous extracts inhibit inflammation in mouse model of pleurisy. Fitoterapia. 2007;8:112-119;

11. De-Paris F, Petry RD, Reginatto F, Gosmann G, Salgueiro JB, Quevedo J, et. al. Pharmacochemical study of aqueous extracts of Passiflora alata Dryander and Passiflora edulis Sims. Acta Farmaceutica Bonaerense. 2002;21:5-8;

12. Chi YS, Jong HG, Son KH, Chang HW, Kang SS, Kim HP. Effects of naturally occurring prenylated flavonoids on enzymes metabolizing arachidonic acid: cyclooxygenases and lipoxygenases. Biochemical Pharmacology. 2001;62:185-1191;

13. Deng J, Zhoua Y, Baia M, Li H, Lic L. Anxiolytic and sedative activities of Passiflora edulis f. flavicarpa. Journal of Ethnopharmacology. 2010:1-6; 
de Melo, A. F.; Muricy, J. M. T. C.; Santos, R. F. Revista Eletrônica de Farmácia Vol. IX (3), $1-15,2012$.

14. Garros IC, Campos ACL, Tâmbara EM, Tenório SB, Torres OJM, Agulham MÂ, et. al. Extrato de Passiflora edulis na Cicatrização de Feridas Cutâneas Abertas em Ratos: Estudo Morfológico e Histológico. Acta Cirúrgica Brasileira. 2006;21(3):55-65;

15. York P. Delineamento de formas farmacêuticas. 2nd ed. Porto Alegre:Artmed; 2005;

16. Agência Nacional de Vigilância Sanitária. Guia de Estabilidade de Produtos Cosméticos / Agência Nacional de Vigilância Sanitária. 1. ed. Brasília (Brasil): ANVISA, 2004;

17. Knorst MT. Desenvolvimento tecnológico de forma farmacêutica plástica contendo extrato Deachyrocline Satureioides (Lom) DC. Compositae [dissertation]. Porto Alegre: Curso de Farmacia/Universidade de Porto; 1991. 228p;

18. ANSI - American National Standards Institute. ASTM D2196-05 Standard Test Methods for Rheological Properties of Non-Newtonian Materials by Rotational (Brookfi eld type) Viscometer. New York:ANSI, 2005;

19. Bhargava HN. The present status of formulation of cosmetic emulsions. Drug Development in Industrial Pharmacy. 1997;13(13):2363-2387;

20. Bugnotto C, Soares G, Laporta LV, Alves MP, Schmidt CA, Limberger JB. Estudo de Estabilidade de Formulação Tópica Contendo Própolis. Disc. Scientia. Série: Ciências da Saúde, Santa Maria. 2006;7(1)1-12. 